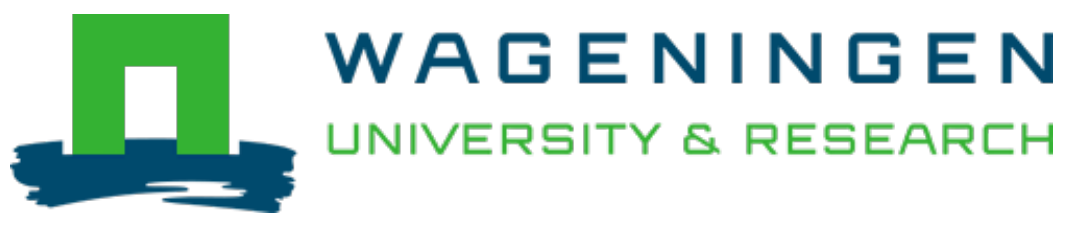

\title{
Relative preference for wooden nests affects nesting behaviour of broiler breeders
}

Applied Animal Behaviour Science

Oever, Anna C.M.; Rodenburg, T.B.; Bolhuis, J.E.; Ven, Lotte J.F.; Hasan, Md Kamrul et al

https://doi.org/10.1016/j.applanim.2019.104883

This article is made publicly available in the institutional repository of Wageningen University and Research, under the terms of article $25 \mathrm{fa}$ of the Dutch Copyright Act, also known as the Amendment Taverne. This has been done with explicit consent by the author.

Article $25 \mathrm{fa}$ states that the author of a short scientific work funded either wholly or partially by Dutch public funds is entitled to make that work publicly available for no consideration following a reasonable period of time after the work was first published, provided that clear reference is made to the source of the first publication of the work.

This publication is distributed under The Association of Universities in the Netherlands (VSNU) 'Article 25fa implementation' project. In this project research outputs of researchers employed by Dutch Universities that comply with the legal requirements of Article $25 \mathrm{fa}$ of the Dutch Copyright Act are distributed online and free of cost or other barriers in institutional repositories. Research outputs are distributed six months after their first online publication in the original published version and with proper attribution to the source of the original publication.

You are permitted to download and use the publication for personal purposes. All rights remain with the author(s) and / or copyright owner(s) of this work. Any use of the publication or parts of it other than authorised under article $25 \mathrm{fa}$ of the Dutch Copyright act is prohibited. Wageningen University \& Research and the author(s) of this publication shall not be held responsible or liable for any damages resulting from your (re)use of this publication.

For questions regarding the public availability of this article please contact openscience.library@,wur.nl 


\title{
Relative preference for wooden nests affects nesting behaviour of broiler breeders
}

\author{
Anna C.M. van den Oever ${ }^{\mathrm{a}, \mathrm{b}, *}, \mathrm{~T}$. Bas Rodenburg ${ }^{\mathrm{b}, \mathrm{c}}$, J. Elizabeth Bolhuis ${ }^{\mathrm{b}}$, Lotte J.F. van de Ven ${ }^{\mathrm{a}}$, \\ Md. Kamrul Hasan ${ }^{\mathrm{d}}$, Stephanie M.W. van Aerle ${ }^{\mathrm{d}}$, Bas Kemp ${ }^{\mathrm{b}}$ \\ ${ }^{a}$ Vencomatic Group, P.O. Box 160, 5520 AD Eersel, the Netherlands \\ ${ }^{\mathrm{b}}$ Adaptation Physiology Group, Wageningen University, P.O. Box 338, $6700 \mathrm{AH}$ Wageningen, the Netherlands \\ ${ }^{\mathrm{c}}$ Department of Animals in Science and Society, Faculty of Veterinary Medicine, Utrecht University, P.O. Box 80.166, 3508 TD Utrecht, the Netherlands \\ ${ }^{\mathrm{d}}$ Behavioural Ecology Group, Wageningen University, P.O. Box 338, 6700 AH Wageningen, the Netherlands
}

\section{A R T I C L E I N F O}

\section{Keywords:}

Broiler breeder

Nest design

Preference test

Behaviour

Welfare

\begin{abstract}
A B S T R A C T
Optimising nest design for broiler breeders has benefits for both the animals and the producers. The welfare of the hens will increase by providing preferred housing, while also reducing eggs laid outside the nests. These floor eggs cause economic losses by compromised automatic egg collection and reduced saleability and hatchability. Attractiveness of nests can involve factors such as seclusion, material and microclimate. In this study, four nest box designs were offered in a relative preference test: a plastic control nest, a plastic nest with a partition to divide the nest in two areas, a plastic nest with a ventilator underneath to create air flow inside the nest and a wooden nest. Six groups of 100 hens and 9 roosters had access to these four nests in a randomised location during the ages of 20 to 34 weeks. Nest and floor eggs were collected five days a week. Camera images from inside the nests made during the ages of 24-25 weeks and 26-27 weeks were analysed for behaviour. This included general activity, nest inspections, nest visits and social interactions. At 32 weeks of age the wooden nests were closed, and the subsequent response of the hens was monitored in terms of number of eggs. We found a clear preference in number of eggs for the wooden nest $(69.3 \pm 1.0 \%)$ compared to the control nest $(15.1 \pm 0.8 \%)$, partition nest $(10.2 \pm 0.5 \%)$ and the ventilator nest $(5.4 \pm 0.4 \%$; $<0.0001$ for difference between all nest designs). The preference for the wooden nest was also reflected in an increased time spent sitting, together with fewer nest inspections and visits per egg laid in the wooden nest. The preference for the wooden nest led to crowding, which caused an increased amount of piling, nest displacement, aggression and head shaking. The fact that the hens were willing to accept the crowded circumstances in these nests, underlines the strength of this preference. After the wooden nests were closed, the hens chose a new nest based on a combination of nest design and location. The control nest was still preferred over the other two plastic designs, although the neighbouring nests were overall preferred to the non-neighbouring nests. This study shows how the material used for nests is an important factor in suitability and should therefore be taken into account when designing nests.
\end{abstract}

\section{Introduction}

When attempting to optimise housing conditions for chickens kept on commercial farms, the main question is what does the hen prefer. Providing nests with a preferred design has benefits for the hens as well as for the producer. The welfare of the hens will likely be increased by meeting their needs and this could also increase the number of eggs laid in the nests as opposed to other locations. Eggs outside the nests are undesirable due to the time consuming manual collection and the reduced hatchability and saleability (van den Brand et al., 2016). This is caused by the fact that floor eggs are often dirty and broken, contain more bacteria on the eggshell and have more cracks than clean nest eggs (Berrang et al., 1997).

Relative preference or choice tests are the most used method to gain insight into the preference of the hens. Hens are offered two or more designs at the same time and their response to this is monitored for a certain amount of time. This response can be studied in terms of different parameters. The number of eggs laid in the nests is often used as a main parameter, as this clearly reflects a choice of the hens. Behaviour exhibited in and around the nest can also be used as a parameter. The

\footnotetext{
* Corresponding author at: Vencomatic Group, P.O. Box 160, 5520 AD Eersel, the Netherlands.

E-mail address: anne.vandenoever@vencomaticgroup.com (A.C.M. van den Oever).
} 
term 'settled' has been used for describing nesting behaviour that would reflect a preference. Originally the term settled was used for a higher portion of time spent in the final laying position (Appleby, 1990; Appleby et al., 1993). More time sitting in the nest, especially in fewer bouts, is currently used more often as a measure for settled behaviour (Cronin et al., 2012). It has also been expanded to the searching phase, where fewer nest inspections and visits per egg are interpreted as more settled nesting behaviour (Freire et al., 1996; Hunniford and Widowski, 2018). Unsettled nesting behaviour can also be caused by negative social interactions, rather than a disliking of the environment. Aggression and displacement behaviour have previously been described in laying hens and can be disruptive to settled nesting behaviour (Freire et al., 1996; Struelens et al., 2008).

Previous research on the nest design preference of broiler breeders has shown that there is a preference for smaller metal nests compared to larger wooden nests, with unpainted rather than black painted walls (Brake, 1985; Holcman et al., 2007). Plastic materials, although commonly used in commercial practice, have not been compared to other materials before. Preferred nest size has also been studied, where smaller nests have been preferred over larger nests by broiler breeders as well as laying hens (Holcman et al., 2007; Ringgenberg et al., 2014). Although the preference of broiler breeders for type of bedding material was inconsistent, concave nest floors were preferred over flat floors and grey nest pads were chosen over other colours (Brake, 1993, 1985; Holcman et al., 2007). Seclusion is thought to be important for laying hens as pre-laying behaviour is more settled in the presence of nest curtains compared to no nest curtains, although no difference in number of eggs was found when comparing nests with sliced curtains to nests with one-piece curtains (Stämpfli et al., 2012; Struelens et al., 2008). In warmer climates, nests are often equipped with perforated nest floors to allow for air flow inside the nest. However, in colder climates chickens are observed to get disturbed by air flows in the nests as they might be sensed as draughts due to the lower temperature (Wim Peters, personal communication, 21 July 2017).

When the preferred nest has been found by hens, they tend to return to this nest every day. This conservatism in nest location has often been described (Appleby et al., 1984; Duncan and Kite, 1989; Riber, 2010; Riber and Nielsen, 2013), which has been suggested to be caused by the last remainders of broodiness, so as to form a clutch of eggs in the same location (Riber, 2010). To our knowledge, no study has investigated the response of hens when their usual nesting location becomes unavailable.

This study aims to compare four nest designs in a relative preference test. The most preferred nest was expected to be a nest with a partition in the middle, as this provides a smaller nest size and more seclusion. After that, we expected that the nest with wooden walls would be preferred over the control nest with plastic walls due to the natural properties of the material. The nest with a ventilator underneath was expected to be least preferred, as this creates an undesired air flow in the nest. Preference was hypothesized to be apparent in number of eggs laid in the respective nests, but also in more settled nesting behaviour. When closing the preferred nest at a later age, the hens were expected to move to the nest nearest their preferred nest independent of the nest design, which reflects their conservatism in location.

\section{Materials and methods}

\subsection{Animals and housing}

The relative preference for nest design was tested with Ross 308 broiler breeders during the winter of $2017 / 2018$. A total of 600 females and 54 males, all non-beak trimmed, were purchased from a commercial rearing farm with raised slatted areas at the age of 20 weeks. The chickens were randomly assigned to six pens, resulting in 100 females and 9 males per pen. The pens were identical in size $(3.4 \times 4.6 \times 2.0 \mathrm{~m}$, length $\times$ width $\times$ height $)$ and layout and were placed in one row. The pens had wire mesh walls, which allowed the animals from different pens to see each other. The litter area $(1.8 \times 4.6 \mathrm{~m})$ was covered with saw dust and gave access to two feeding lines, which were partially covered with grids to create separate female and male feeding areas. The slatted area $(1.15 \times 4.6 \mathrm{~m})$ was raised by $0.5 \mathrm{~m}$ and gave access to 25 drinking nipples and a row of four nests. The four nests were of a different design (see below) and placed in a different location in each pen using block randomisation to resolve location preference in the pen. The lay-out of the pen was according to commercial practice in the Netherlands, although the stocking density ( 7 birds per $\mathrm{m}^{2}$ ), nest space per hen $\left(207 \mathrm{~cm}^{2}\right.$ per hen) and birds per drinking nipple ( 4 birds per nipple) were lower than what is seen in commercial practice to be in accordance with the Dutch Experiments on Animals Act (IVD Utrecht, 2019). This study was approved by the Dutch Central Authority for Scientific Procedures on Animals (CCD) and is registered under application number AVD1040020173027.

The group nests were of a rollaway type, designed specifically for this study. The nests were $1.15 \mathrm{~m}$ wide, $0.45 \mathrm{~m}$ deep and measured $0.6 \mathrm{~m}$ high at the front and $1.0 \mathrm{~m}$ high at the back. The nests were raised by $10 \mathrm{~cm}$ from the slats, so the birds had easy access to the nests. All nests had a green rubber nest floor slanting towards the front. The front of the nest was closed by two solid red nest curtains, made of PVC coated fabric, leaving an opening of $20 \times 23 \mathrm{~cm}$ in the middle. Four types of nests were tested: the control, partition and ventilator nest all had black HDPE plastic side and back walls, whereas the wooden nest had dark brown epoxy coated birch plywood side and back walls. The partition nest had a plastic partition made of the same material as the wall in the middle of the nest floor of $20 \mathrm{~cm}$ high. All wall materials were smooth, solid and $12 \mathrm{~mm}$ thick. The ventilator nest had a low noise ventilator (Tristar VE-5904) underneath the nest to create an air flow $(0.2 \mathrm{~m} / \mathrm{s})$ inside the nest, as air could pass between the walls and the floor of the nest.

The house was lit with artificial LED-lighting, creating a photoperiod schedule according to commercial practice. At 20 weeks of age, the animals had $10 \mathrm{~h}$ of light (8:00 to $18: 00 \mathrm{~h}$ ) at $10 \mathrm{~lx}$ measured at bird height. This was gradually increased with age to $14 \mathrm{~h}$ of light (6:00 to $20: 00 \mathrm{~h}$ ) at $60 \mathrm{~lx}$ at bird height at the age of 26 weeks. The temperature was maintained at $18 \pm 1{ }^{\circ} \mathrm{C}$, according to the management guidelines. Food was provided at lights-on, given at a restricted amount according to commercial practice. At 20 weeks of age the animals received $105 \mathrm{~g}$ per individual per day, which gradually increased to $165 \mathrm{~g}$ per individual per day at the age of 26 weeks. Random samples of 60 birds were weighed weekly. Water was provided at lights-on for $3 \mathrm{~h}$ and for $30 \mathrm{~min}$ in the afternoon. The nests were opened to the hens from $30 \mathrm{~min}$ before lights-on until $30 \mathrm{~min}$ after lights-out, from the day after the first egg was found ( 23 weeks of age). The birds were kept until the age of 34 weeks.

\subsection{Data collection}

In order to assess preference for the different nest designs, our primary outcome variable was the number of eggs laid in each nest. Eggs were collected separately from each nest and from other areas of the pen (noted as floor eggs). This was done three times a day, five days per week between 8:00 and 16:00 h. Collection continued until the experiment was terminated at 34 weeks of age.

Behavioural data were recorded from video images, using four infrared cameras IPC-BT508V-20SC (Techage, Shenzhen, China) placed through a hole in the ceiling of the nests to film inside the four nests of each pen simultaneously. Digital cameras FI9803EP (Foscam, Shenzhen, China) were also mounted on the pen walls recording the entrances of the nests. After a pen was filmed for one day, the cameras were moved to the next pen. This allowed for filming three pens per week, taking two weeks to film all pens involved in this study. The recordings were made between 24-27 weeks of age, resulting in two days per pen observed with two weeks between the two days for each 
Table 1

Ethogram of behaviours inside the nest recorded using a 10 min scan sampling method.

\begin{tabular}{ll}
\hline Behaviour & Description \\
\hline Resting & $\begin{array}{l}\text { Sitting with neck folded backwards with head tucked between } \\
\text { feathers }\end{array}$ \\
Sitting & Sitting on the nest floor \\
Standing & Standing in an upright position \\
Walking & $\begin{array}{l}\text { Moving at least two steps } \\
\text { Piling }\end{array}$ \\
& $\begin{array}{l}\text { Sitting on top or under a conspecific with at least one body part } \\
\text { (head, wing, rump, tail) }\end{array}$
\end{tabular}

Table 2

Ethogram of behaviours inside the nest recorded (as frequencies) using the behaviour sampling method.

\begin{tabular}{ll}
\hline Behaviour & Description \\
\hline $\begin{array}{l}\text { Head shaking } \\
\text { Head pecking }\end{array}$ & $\begin{array}{l}\text { Shaking only the head, counted in bouts of 5s } \\
\text { Pecking to the head or neck of conspecifics, counted in bouts of } \\
5 \mathrm{~s}\end{array}$ \\
Feather pecking & $\begin{array}{l}\text { Pecking the feathers of conspecifics (gentle or severe), counted } \\
\text { in bouts of } 5 \mathrm{~s}\end{array}$ \\
Displacement & $\begin{array}{l}\text { Forcing another hen to move (including threats without } \\
\text { physical contact) } \\
\text { Placing head in the nest box without entering it } \\
\text { Nest inspection }\end{array}$ \\
Nest visit &
\end{tabular}

pen. Recordings were made from the moment the nests were opened in the morning until 17:00 h.

Behavioural observations inside the nest were done between 9:00-11:00 $\mathrm{h}$ and 14:00-16:00 $\mathrm{h}$, so as to include both a period during and after the peak of egg laying. Behaviours as listed in Table 1 were observed using scan sampling with a 10-min interval. Frequencies of behaviours as listed in Table 2 were observed using a behavioural sampling method in which $5 \mathrm{~min}$ per $30 \mathrm{~min}$ of video recordings were analysed continuously.

At the age of 32 weeks a preference for the wooden nest was found in 5 out of 6 pens, so the wooden nests in all pens were closed in order to study subsequent preference. The number of eggs laid in each nest as well as floor eggs were then recorded for 9 days as described before. One pen was randomly chosen and excluded from this part of the experiment, as it was needed for other research purposes.

In order to explore what factors correlated to the differences in preference for the nest designs, the nests were physically characterised. The light intensity, rounded to the nearest $\mathrm{lx}$, inside each nest was measured with lux meter 540 (Testo, Almere, The Netherlands) held facing up at $20 \mathrm{~cm}$ height from the nest floor in the middle of the nest. Air temperature with a precision of $0.01^{\circ} \mathrm{C}$, was measured inside the nests of two pens every $10 \mathrm{~min}$ for $48 \mathrm{~h}$ using data loggers 174 (Testo, Almere, The Netherlands). The electrostatic properties of the control and wooden nest were measured using the electrostatic field meter EFM51 (Wolfgang Warmbier, Hilzingen, Germany; precision of $1 \mathrm{~V}$ ) and surface resistance meter METRISO 2000 - 541C (Wolfgang Warmbier, Hilzingen, Germany; precision of $1 \mathrm{M} \Omega$ ) with two resistance probes model 850.

\subsection{Statistical analysis}

All statistical analyses were performed with SAS (version 9.4). P values below 0.05 were considered significant and the MIXED procedure was used to perform general linear mixed models (and the GLIMMIX procedure where necessary). The assumptions of homogeneity of variance and normally distributed errors were examined visually using the conditional studentized residuals plots. In order to satisfy these assumptions, the number of eggs per nest and the behaviours walking, resting, piling, nest visits, nest inspections, displacement, feather pecking, head pecking and head shaking were square root transformed and the MIXED procedure was used. Results are shown as non-transformed means with corresponding standard errors. For the behaviours nest displacement, feather peck and head peck the GLIMMIX procedure was used with a Poisson distribution. For pairwise comparisons, Tukey's post hoc test was performed.

Behavioural observations between 9:00-11:00 $\mathrm{h}$ were summed and named AM, while observations between 14:00-16:00 h were summed as PM. As fixed effects nest design, age and time of day were included, as well as the interactions between these variables. Pen was included as a random effect in all models. Sitting, standing, walking, resting and piling were analysed as the percentages of total number of observations. For the data on eggs laid per nest after closing the wooden nests, the remaining nests were given a proximity label. Nests directly adjacent to the wooden nests were labelled 'neighbour' and the other nests were labelled as 'non-neighbour'. If the wooden nest was in the corner, there was one neighbouring nest, otherwise two. The model for eggs per nest after closing the wooden nest included this proximity label as a fixed effect besides nest design, age and time of day, as well as the interactions between these variables. Pen was included as a random effect. Percentages of floor eggs were calculated for 9 days before closing the wooden nests and 9 days after closing these nests. Nest open or closed was included as a fixed effect, pen as a random effect.

For light intensity and electrostatic measurements no statistical analysis was performed, as all light intensity measurements were equal and the electrostatic measures were measured without replication. Air temperature was analysed with nest design and nest closed or open as fixed effects, while including pen as a random effect.

\section{Results}

\subsection{Distribution of eggs}

During the course of the experiment 31,223 eggs were laid in the nests. The percentage of floor eggs over the entire experiment was $5.8 \pm 2.8 \%$. For the development of percentages of eggs in nests over time, see Fig. 1. The interaction between nest design and age was found to be significant $\left(F_{27,2696}=3.03, p<0.0001\right)$. In week 23 the wooden nest did not differ significantly yet from the partition nest, but from then onwards there was a strong preference for the wooden nest. The overall percentage of eggs in the four nest designs were found to all differ significantly from each other (Tukey test, $\mathrm{p}<0.0001$ ). Most of the eggs were laid in the wooden nest $(69.3 \pm 1.0 \%)$, followed by the control nest $(15.1 \pm 0.8 \%)$, the partition nest $(10.2 \pm 0.5 \%)$ and the ventilator nest $(5.4 \pm 0.4 \%)\left(F_{3,2696}=738.1, \mathrm{p}<0.0001\right)$. Percentage of egg laying hens was on average $51.2 \pm 6.1 \%$ and $86.9 \pm 5.7 \%$ during the behavioural observation weeks $24-25$ and 26-27 respectively. The proportion of eggs laid between $8: 00-12: 00 \mathrm{~h}$ was $51.0 \pm 3.0 \%$ and between $12: 00-16: 00 \mathrm{~h}$ was $15.4 \pm 1.5 \%$, so the chosen behavioural observation time frames fell during and after peak laying time.

\subsection{Behaviour at age $24-27$ weeks}

For the time budget, the only behaviour differing between the nest designs was sitting (Table 3). More sitting was found in the wooden nest compared to the partition and ventilator nest, although no significant difference was found with the control nest. The number of inspections and visits expressed per egg was significantly lower in the wooden nest and significantly higher in the ventilator nest compared to the other nest designs (Table 4). Behaviours piling, displacement, feather pecking, head pecking and head shaking were all observed significantly more in the wooden nest compared to the other nest designs (Table 5). Piling behaviour was significantly lower in the partition and ventilator nest compared to the other nest designs. The maximum number of hens seen in the nests were $4,5,5$ and 11 for respectively the ventilator, 


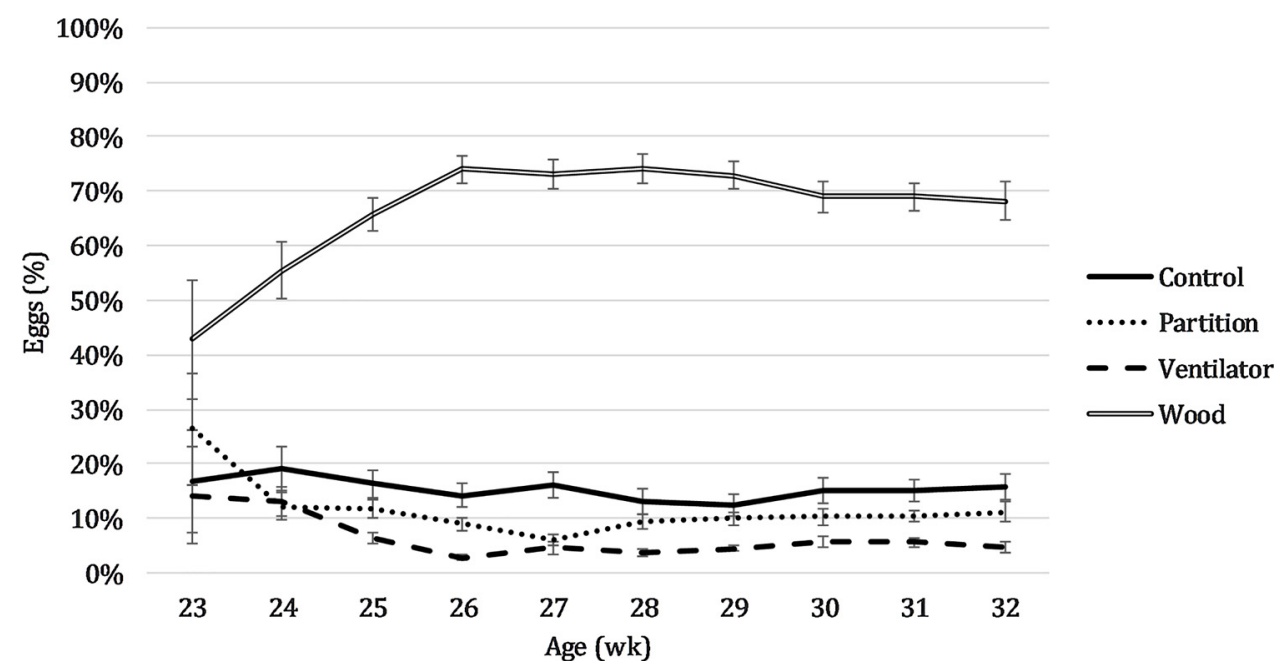

Fig. 1. The distribution of eggs (\%) over the four nest designs per week of age. Error bars depict the standard error.

partition, control and wooden nest.

The number of nest inspections per nest visit declined with age $\left(\mathrm{F}_{1,232}=16.2, \mathrm{p}<0.0001\right)$ from $2.19 \pm 0.15$ at age $24-25$ weeks to $1.58 \pm 1.15$ at $26-27$ weeks of age.

\subsection{Closing of the wooden nest}

After closing the wooden nests, the percentage of eggs found in the remaining nests was the result of an interaction between nest design and proximity label $\left(\mathrm{F}_{2}, 321=18.6, \mathrm{p}<0.0001\right)$. Most eggs were found in the neighbouring control nest, followed by the neighbouring partition nest (Fig. 2). Fewer eggs were found in the neighbouring ventilator nest and non-neighbouring control nest. The non-neighbouring partition and ventilator nest received the fewest eggs. Closing the wooden nests did not significantly affect percentage of floor eggs, which was found to be $2.6 \pm 0.3 \%$ before and $2.9 \pm 0.2 \%$ after closing the wooden nests $\left(\mathrm{F}_{1,96}=0.5, \mathrm{p}=0.48\right)$. Percentage of egg laying hens was on average $73.5 \pm 3.6 \%$ during this period.

\subsection{Physical characteristics}

Light intensity inside the nests was found to be $0 \mathrm{~lx}$ in all nests. Air temperature inside the nests was found to be the result of the interaction between nest design and whether the nest was open or closed $\left(\mathrm{F}_{3,2295}=190.7, \mathrm{p}<0.0001\right)$. The temperature in the wooden nest was $1.42 \pm 0.06^{\circ} \mathrm{C}$ higher during the time the nests were open to the birds compared to the other nest designs, but this difference was not found during the time the nests were closed. The electrostatic field measurements in the control nest were numerically higher than in the wooden nest, which can be found in Table 6 . The surface resistance of the plastic wall of the control nest was measured at 1,000,000 $\mathrm{M} \Omega$, while the wooden wall was found to be $4 \mathrm{M} \Omega$.

\section{Discussion}

This study shows a strong relative preference of the broiler breeder hens for the wooden nest. The large majority of the eggs were laid in the wooden nest and this suggests that the hens found this nest design best suited for egg laying, which is the ultimate purpose of a nest. The lower number of nest inspections (looking into the nest) and nest visits (entering the nest) per egg in the wooden nest compared to the other nest designs strengthens the suggestion that this nest is found to be more suitable by the hens (Appleby and Hughes, 1995; Freire et al., 1996). Furthermore, an increased amount of sitting behaviour was observed in the wooden nests compared to the other nest designs. More sitting behaviour has been linked to more settled nesting as well (Cronin et al., 2012; Freire et al., 1996). Since chickens are known to be gregarious in their nesting behaviour, the question remains whether all individuals prefer the wooden nests or that the first hens chose this nest design and the other hens joined them (Appleby and McRae, 1986). The fact that the wooden nest was preferred in 5 out of 6 pens does suggest that the majority of hens prefer this nest design, regardless of gregarious motivations.

Contrary to our predictions, the partition nest design was not preferred by our broiler breeder hens. The partition was thought to create two smaller, more secluded areas for the birds. Smaller sized nests have previously been found to be preferred by broiler breeders as well as laying hens (Holcman et al., 2007; Ringgenberg et al., 2014). More secluded nests in terms of nest curtains also resulted in more settled nesting behaviour in laying hens (Ringgenberg et al., 2015; Stämpfli et al., 2012; Struelens et al., 2008). In this study however, the partition nest was found to be less preferred than the wooden and control nest by the hens. The partition was meant to create extra corners for the hens to sit in, but the partition was placed in line with the nest entrance and hens sitting against this partition would be in clear view of their pen mates. So while creating extra corners, these were perhaps unattractive due to their limited seclusion. In addition, the fact that the partition was

Table 3

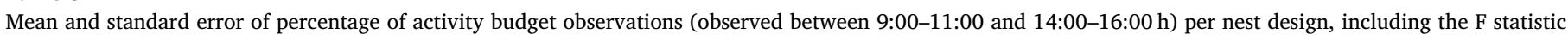
and corresponding $\mathrm{P}$ value.

\begin{tabular}{|c|c|c|c|c|c|c|}
\hline Parameter & Control & Partition & Ventilator & Wood & F statistic & $P$ value \\
\hline Sitting (\%) & $35.6 \pm 7.0^{\mathrm{ab}}$ & $32.8 \pm 6.3^{\mathrm{b}}$ & $29.2 \pm 6.2^{\mathrm{b}}$ & $52.1 \pm 3.6^{\mathrm{a}}$ & $\mathrm{F}_{3,89}=3.72$ & 0.0142 \\
\hline Walking (\%) & $33.3 \pm 7.1$ & $39.7 \pm 6.6$ & $35.8 \pm 6.5$ & $36.2 \pm 3.4$ & $\mathrm{~F}_{3,89}=2.07$ & 0.1104 \\
\hline Standing (\%) & $9.0 \pm 4.2$ & $18.6 \pm 5.7$ & $8.3 \pm 3.3$ & $7.4 \pm 1.8$ & $F_{3,89}=0.24$ & 0.8705 \\
\hline Resting (\%) & $1.3 \pm 1.0$ & $0.6 \pm 0.6$ & $5.9 \pm 4.2$ & $0.2 \pm 0.2$ & $\mathrm{~F}_{3,89}=1.45$ & 0.2339 \\
\hline
\end{tabular}

${ }^{\mathrm{a}, \mathrm{b}}$ Means lacking a common superscript within a row differ $(\mathrm{p}<0.05)$. 
Table 4

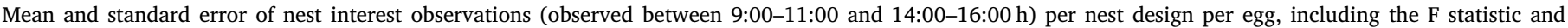
corresponding $\mathrm{P}$ value.

\begin{tabular}{|c|c|c|c|c|c|c|}
\hline Parameter & Control & Partition & Ventilator & Wood & F statistic & $\mathrm{P}$ value \\
\hline Inspections per egg & $9.4 \pm 3.5^{\mathrm{b}}$ & $8.0 \pm 2.8^{\mathrm{b}}$ & $12.2 \pm 2.1^{\mathrm{a}}$ & $1.6 \pm 0.3^{c}$ & $\mathrm{~F}_{3,42}=10.79$ & $<0.0001$ \\
\hline Visits per egg & $3.4 \pm 0.8^{b}$ & $4.1 \pm 1.2^{\mathrm{ab}}$ & $6.2 \pm 1.1^{\mathrm{a}}$ & $1.0 \pm 0.2^{\mathrm{c}}$ & $\mathrm{F}_{3,42}=11.68$ & $<0.0001$ \\
\hline
\end{tabular}

a,b,c Means lacking a common superscript within a row differ $(\mathrm{p}<0.05)$.

only sitting hen height might be insufficient to create the idea of a more secluded nest.

The ventilator nest was least preferred, which is in line with our predictions. The percentage of eggs found in the ventilator nest was significantly lower than in the other nests and the number of nest visits and inspections per egg were significantly higher. Both findings are signs of disliking the nest. Good ventilation in poultry houses is essential to regulate air quality for the welfare of the chickens as well as the farm workers (Kocaman et al., 2006; Whyte, 1993). Depending on the temperature and speed of the air, ventilation can also cause heat loss and thermoregulatory responses to prevent heat loss. Although the air flow in our experiment was relatively low compared to these studies, the temperature in our experiment was set to only $18{ }^{\circ} \mathrm{C}$ and the animals were fed restrictively. These values combined will likely create a nest with the feeling of a draught, which the hens found unattractive for an egg laying location. It is unlikely that noise or vibration caused by the ventilator influenced nest choice, as the ventilator was selected on the characteristics of low-noise and did not have any contact with the nest to cause vibrations.

As for the preference of wood compared to the plastic material of the other nest designs, we included some characterising measurements to tease apart possible reasons behind the preference for the wooden material. The nest designs were all providing equally dark spaces, so this cannot explain the preference for wood. Since the nests were so dark, we assume that the colour difference of dark brown wood versus black plastic was not involved in nest choice. The air temperature was higher in the wooden nests during the time that the nests were open, which is likely caused by the increased number of hens using the nest compared to the other nests. The increased temperature could also be explained by the fact that wood is a better insulator. When the nests were closed, the nest designs did not significantly differ in air temperature and this also seems to suggest that temperature is not a factor in preference for wood. Albeit measured in one nest of each design only, our measurements indicate a potential difference in terms of electrostatic properties between the two materials. The plastic control nest had higher electrostatic fields and surface resistance than the wooden nest, although we could not analyse this difference statistically. Only two studies have been done on the effects of electric fields on poultry behaviour and performance. The results of these studies were inconsistent and focussed on low stray voltage between 0-18 V (Vivaldi et al., 1996; Worley and Wilson, 2000). In this study we found electrostatic fields of over $70 \mathrm{~V}$ in the plastic nest, which raises the question on whether this could be attributed to the lower preference for this material. More research is needed to clarify the effects of electrostatic properties of materials on chickens as well as other properties not included in this study, such as smell, sound and light reflection. These factors are known to be well sensed by chickens and might be involved in selecting the most attractive nest (Collias and Joos, 1953; Jones and Roper, 1997; Prescott and Wathes, 1999).

The strong preference for the wooden nests caused crowding in these nests. This is reflected by an increased frequency of piling behaviour. The crowding also seemed to have led to increased aggressive behaviour between the hens in the form of nest displacement, feather and head pecking. Head shaking was also observed more in the wooden nest and this behaviour is known to be increasingly performed during conflict situations or in stressful environments (Hughes, 1983; Mason, 1991). Altogether it seems that the wooden nests turned into a negative environment due to the crowding. However, the hens did not change their location for oviposition in response to this crowding, but consistently returned to the wooden nest. We interpret this as a sign of the strength of their preference for this nest design. One of the ways to measure the strength of preference, is by making the animals work or pay a high price for their desired goal (Dawkins, 1983; Duncan, 1991). The biological equivalent of 'paying a high price' could be the amount of aversion an animal is willing to accept in order to reach its desired goal. So when these hens were willing to accept the negative circumstances of crowding in order to lay their egg in the wooden nest, this shows a strong preference for this nest design. It should be noted, though, that the frequencies of behaviours observed were not corrected for the number of hens per nest, and therefore the negative social interactions encountered per hen may have been overestimated in the preferred nests. Furthermore, the crowding could have affected nest choice as the wooden nest was inaccessible for hens at busy moments.

Where a clear preference is seen at the earlier ages, location of the nests starts to become a factor in nest choice at a later age. When the wooden nests were closed at the age of 32 weeks, the hens showed a preference for nest design depending on location. When comparing the same nest design, the nests neighbouring the wooden nest received significantly more eggs than the nests further away. This is in line with previous studies on nesting location with laying hens, reporting a conservatism in egg laying location (Appleby et al., 1984; Duncan and Kite, 1989; Riber, 2010; Riber and Nielsen, 2013). The finding that the number of nest inspections per nest visit decreased with age also suggests that the hens had made their choice and nest exploration was kept to a minimum. Tracking individual nest choices would be needed to confirm this suggestion. The preference for the wooden nest increased from 23 to 26 weeks of age and thereafter remained stable. This initial period of nest exploration at the onset of lay therefore determines the

Table 5

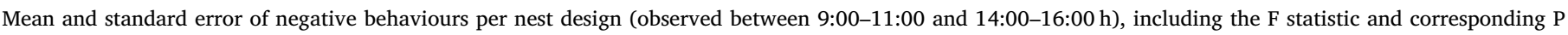
value. Piling is expressed in percentage of total scan observations, the other parameters as frequency per 5 min observation.

\begin{tabular}{|c|c|c|c|c|c|c|}
\hline Parameter & Control & Partition & Ventilator & Wood & F statistic & $P$ value \\
\hline Piling & $8.75 \pm 1.51^{b}$ & $0.97 \pm 0.57^{c}$ & $1.88 \pm 0.79^{c}$ & $28.75 \pm 2.82^{\mathrm{a}}$ & $\mathrm{F}_{3,3593}=50.45$ & $<0.0001$ \\
\hline Displacement & $0.17 \pm 0.05^{\mathrm{b}}$ & $0.13 \pm 0.04^{\mathrm{b}}$ & $0.08 \pm 0.04^{\mathrm{b}}$ & $0.95 \pm 0.21^{\mathrm{a}}$ & $\mathrm{F}_{3,377}=16.17$ & $<0.0001$ \\
\hline Feather pecking & $0.64 \pm 0.18^{\mathrm{b}}$ & $0.28 \pm 0.09^{\mathrm{b}}$ & $0.64 \pm 0.21^{\mathrm{b}}$ & $1.55 \pm 0.24^{\mathrm{a}}$ & $\mathrm{F}_{3,377}=16.40$ & $<0.0001$ \\
\hline Head pecking & $0.58 \pm 0.16^{\mathrm{b}}$ & $0.27 \pm 0.11^{\mathrm{b}}$ & $0.29 \pm 0.11^{\mathrm{b}}$ & $2.34 \pm 0.41^{\mathrm{a}}$ & $\mathrm{F}_{3,377}=27.58$ & $<0.0001$ \\
\hline Head shaking & $1.26 \pm 0.33^{\mathrm{b}}$ & $0.72 \pm 0.18^{\mathrm{b}}$ & $0.99 \pm 0.23^{\mathrm{b}}$ & $3.83 \pm 0.93^{\mathrm{a}}$ & $\mathrm{F}_{3,377}=14.26$ & $<0.0001$ \\
\hline
\end{tabular}

${ }^{\mathrm{a}, \mathrm{b}, \mathrm{c}}$ Means lacking a common superscript within a row differ $(\mathrm{p}<0.0001)$. 


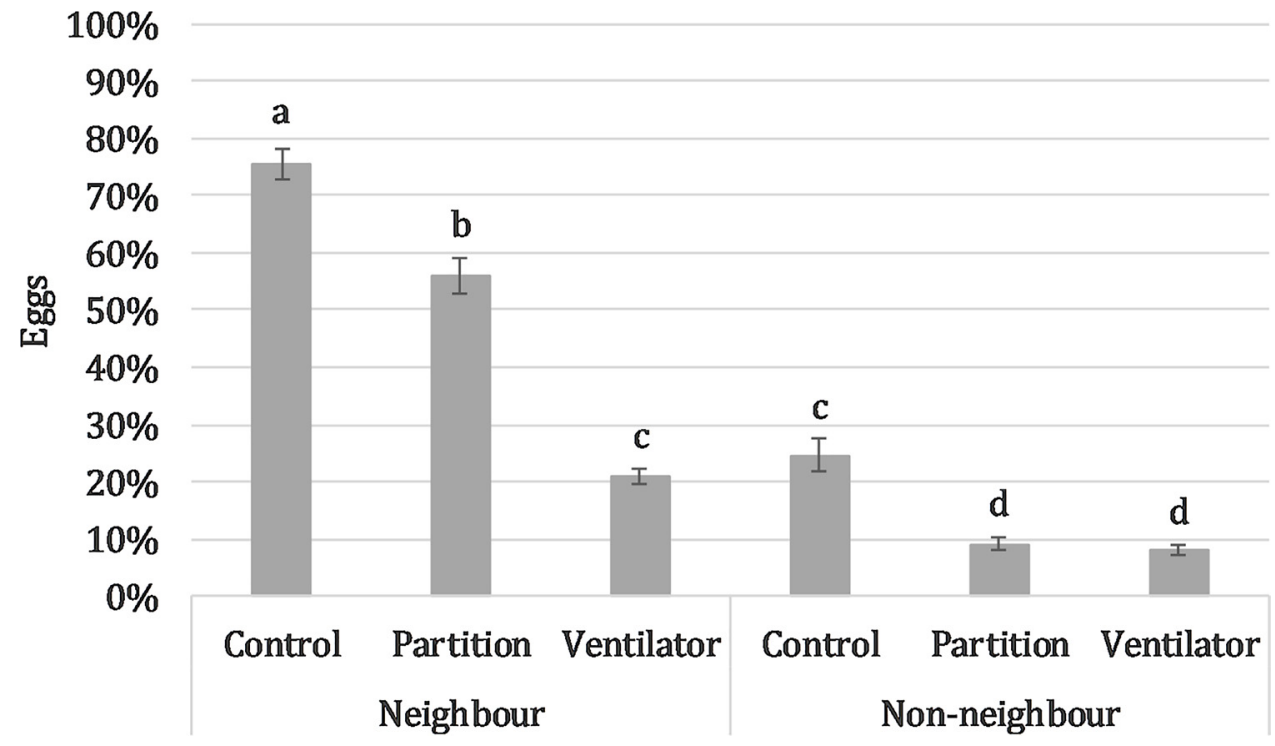

Fig. 2. The distribution of eggs (\%) over the remaining three nest designs after closing the wooden nests at 32 weeks of age, separated for the proximity labels 'neighbour' and 'non-neighbour'. Error bars depict the standard error. Bars lacking a common superscript differ significantly $(\mathrm{P}<0.01)$.

Table 6

Electrostatic fields measured in one control nest and one wooden nest, expressed in volts.

\begin{tabular}{lll}
\hline Part of nest & Control & Wood \\
\hline Entrance & 8 & 7 \\
Nest floor & 7 & 4 \\
Nest curtain & 67 & 9 \\
Side wall & 75 & 8
\end{tabular}

nest location for the rest of the production period, which is an important message for commercial producers. Once hens have found a nest location, however unsuitable for egg quality, it proves to be difficult to change this preference.

\section{Conclusion}

From this study we conclude that a strong preference of broiler breeder hens for wooden nests over plastic nests is apparent, when offered in a relative choice test. This preference was demonstrated by a higher proportion of eggs laid in this nest and more settled nesting behaviour. It also led to crowding, causing piling and aggressive behaviour in the wooden nest. The hens were willing to accept this environment as they continuously returned to the nest. Closing the wooden nest led to a new nest choice, which was the result of an interaction between nest design and proximity to the closed wooden nest. This study shows how the material used for nests is an important factor in suitability and should therefore be taken into account when designing nests.

\section{Acknowledgements}

Many thanks to Gust Fleerakkers, Theo van der Wal, Annemieke Renders and Ronald Bax (Vencomatic Group BV) for their technical assistance and taking care of the animals. This work was supported by Vencomatic Group, Eersel, the Netherlands.

\section{References}

Appleby, M.C., 1990. Behaviour of laying hens in cages with nest sites. Br. Poult. Sci. 31, 71-80. https://doi.org/10.1080/00071669008417232.

Appleby, M.C., Hughes, B.O., 1995. The Edinburgh Modified Cage for laying hens. Br.
Poult. Sci. 36, 707-718. https://doi.org/10.1080/00071669508417815.

Appleby, M.C., McRae, H.E., 1986. The individual nest box as a super-stimulus for domestic hens. Appl. Anim. Behav. Sci. 15, 169-176. https://doi.org/10.1016/0168 1591(86)90062-6.

Appleby, M.C., McRae, H.E., Duncan, I.J.H., Bisazza, A., 1984. Choice of social conditions by laying hens. Br. Poult. Sci. 25, 111-117. https://doi.org/10.1080/ 13632758408454848.

Appleby, M.C., Smith, S.F., Hughes, B.O., 1993. Nesting, dust bathing and perching by laying hens in cages: effects of design on behaviour and welfare. Br. Poult. Sci. 34, 835-847. https://doi.org/10.1080/00071669308417644.

Berrang, M.E., Frank, J.F., Buhr, R.J., Bailey, J.S., Cox, N.A., Mauldin, J.M., 1997. Microbiology of sanitized broiler hatching eggs through the egg production period. J. Appl. Poult. Res. 6, 298-305. https://doi.org/10.1093/japr/6.3.298.

Brake, J., 1993. Influence of nest pad color on nest preference, percentage of floor eggs, and egg production of broiler breeder hens. Poult. Sci. 72, 1663.

Brake, J., 1985. Comparison of two nesting materials for broiler breeders. Poult. Sci. $2263-2266$.

Collias, N., Joos, M., 1953. The spectrographic analysis of sound signals of the domestic fowl. Behaviour 5, 175-188.

Cronin, G.M., Barnett, the late, J.L., Hemsworth, P.H., 2012. The importance of pre-laying behaviour and nest boxes for laying hen welfare: a review. Anim. Prod. Sci. 52, 398-405. https://doi.org/10.1071/AN11258.

Dawkins, M.S., 1983. Battery hens name their price: consumer demand theory and the measurement of ethological "needs.". Anim. Behav. 31, 1195-1205. https://doi.org/ 10.1016/S0003-3472(83)80026-8.

Duncan, I.J.H., 1991. Measuring preferences and the strength of preferences. Poult. Sci. $71,658-663$.

Duncan, I.J.H., Kite, V.G., 1989. Nest site selection and nest-building behaviour in domestic fowl. Anim. Behav. 37, 215-231. https://doi.org/10.1016/0003-3472(89) 90112-7.

Freire, R., Appleby, M.C., Hughes, B.O., 1996. Effects of nest quality and other cues for exploration on pre-laying behaviour. Appl. Anim. Behav. Sci. 48, 37-46. https://doi. org/10.1016/0168-1591(95)01023-8.

Holcman, A., Malovrh, Š., Štuhec, I., 2007. Choice of nest types by hens of three lines of broiler breeders. Br. Poult. Sci. 48, 284-290. https://doi.org/10.1080/ 00071660701370475.

Hughes, B.O., 1983. Headshaking stimuli in fowls: the effect of environmental. Appl. Anim. Ethol, 11, 45-53.

Hunniford, M.E., Widowski, T.M., 2018. Curtained nests facilitate settled nesting behaviour of laying hens in furnished cages. Appl. Anim. Behav. Sci. 202, 39-45. https:// doi.org/10.1016/j.applanim.2018.01.016.

IVD Utrecht, 2019. Wet op de dierproeven [WWW Document]. URL https://www.ivdutrecht.nl/assets/Beleidsdocumenten-EN/20171113-IVD0118-bijlage-Wet-op-dedierproeven-ENG-vertaling-November-2017.pdf (accessed 1.4.19).

Jones, R.B., Roper, T.J., 1997. Olfaction in the domestic fowl: a critical review. Physiol. Behav. 62, 1009-1018. https://doi.org/10.1016/S0031-9384(97)00207-2.

Kocaman, B., Esenbuga, N., Yildiz, A., Laçin, E., Macit, M., 2006. Effect of environmental conditions in poultry houses on the performance of laying hens. Int. J. Poult. Sci. 5, 26-30. https://doi.org/10.3923/ijps.2006.26.30.

Mason, G.J., 1991. Stereotypies: a critical review. Anim. Behav. 41, 1015-1037. https:// doi.org/10.1016/S0003-3472(05)80640-2.

Prescott, N.B., Wathes, C.M., 1999. Spectral sensitivity of the domestic fowl (Gallus g. domesticus). Br. Poult. Sci. 40, 332-339. https://doi.org/10.1080/00071669987412.

Riber, A.B., 2010. Development with age of nest box use and gregarious nesting in laying hens. Appl. Anim. Behav. Sci. 123, 24-31. https://doi.org/10.1016/j.applanim.2009. 
12.016 .

Riber, A.B., Nielsen, B.L., 2013. Changes in position and quality of preferred nest box: effects on nest box use by laying hens. Appl. Anim. Behav. Sci. 148, 185-191.

Ringgenberg, N., Fröhlich, E.K.F., Harlander-Matauschek, A., Toscano, M.J., Würbel, H., Roth, B.A., 2015. Effects of variation in nest curtain design on pre-laying behaviour of domestic hens. Appl. Anim. Behav. Sci. 170, 34-43.

Ringgenberg, N., Fröhlich, E.K.F., Harlander-Matauschek, A., Würbel, H., Roth, B.A., 2014. Does nest size matter to laying hens? Appl. Anim. Behav. Sci. 155, 66-73.

Stämpfli, K., Buchwalder, T., Fröhlich, E.K.F., Roth, B.A., 2012. Influence of front curtain design on nest choice by laying hens. Br. Poult. Sci. 53, 553-560. https://doi.org/10. 1080/00071668.2012.725201.

Struelens, E., Van Nuffel, A., Tuyttens, F.A.M., Audoorn, L., Vranken, E., Zoons, J., Berckmans, D., Ödberg, F., Van Dongen, S., Sonck, B., 2008. Influence of nest seclusion and nesting material on pre-laying behaviour of laying hens. Appl. Anim. Behav. Sci. 112, 106-119. https://doi.org/10.1016/j.applanim.2007.07.010.

van den Brand, H., Sosef, M.P., Lourens, A., van Harn, J., 2016. Effects of floor eggs on hatchability and later life performance in broiler chickens. Poult. Sci. 95, 1025-1032. https://doi.org/10.3382/ps/pew008.

Vivaldi, G., Silversides, F.G., Boily, R., Villeneuve, P., Joncas, R., 1996. Effects of chopped sinusoidal voltages on the behavior and performance of laying hens. Can. Agric. Eng. 38, 99-105.

Whyte, R.T., 1993. Aerial pollutants and the health of poultry farmers. Worlds Poult. Sci. J. 49, 139-156.

Worley, J.W., Wilson, J.L., 2000. Effects of stray voltage on laying habits of broiler breeders. Am. Soc. Agric. Eng. 16, 723-729. 